\title{
DEBATE
}

\section{Banning outdoor smoking is scientifically justifiable}

Simon Chapman has argued that smoking should not be banned in outdoor public venues such as hospital patios, beaches, and outdoor sporting areas, and this might also encompass building entrances, waiting lines for cinema tickets, and outdoor cafés. However, failure to ban smoking in such venues may expose non-smokers to levels of environmental tobacco smoke (ETS) as high or higher than received in indoor spaces where smoking is unrestricted.

The reality of atmospheric dispersion of ETS in outdoor settings is this: individual cigarettes are point sources of air pollution and, therefore, smoking in groups becomes an area source. Outdoor air pollutants from individual point sources are subject to plume rise if the temperature of the smoke plume is hotter than the surrounding air. However, if the plume has a small cross-section, as for a cigarette, it will rapidly cool and lose its upward momentum, and then will subside as the combustion particles and gases are heavier than air. Thus, in the case of no wind, the cigarette plume will rise to a certain height and then descend. In a case where a group of smokers are sitting in an outdoor cafe, on a hospital patio, or in stadium seats, their smoke will tend to saturate the local area with ETS.

Where there is wind, the amount of thermally induced plume rise will be inversely proportional to the wind velocity-doubling the wind velocity will halve the plume rise. In this case, the cigarette plume will resemble a cone tilted at an angle to the vertical. The width of the cone and its angle with the ground will depend upon the wind velocity: a higher wind will create a more horizontal cone, a smaller cone angle, and a higher concentration of ETS for downwind non-smokers. If there are multiple cigarette sources, the downwind concentrations will consist of multiple intersecting cones-that is, overlapping plumes. As the wind direction changes, ETS pollution will be spread in various directions, fumigating downwind non-smokers. ETS contains a large quantity of respirable particles, which can cause breathing difficulties for those with chronic respiratory diseases, or trigger an asthmatic attack in those with disabling asthma. For the remainder of non-smokers, ETS causes eye, nose, and throat irritation, just like any other noxious outdoor fumes, such as bus exhaust. If smoking is freely permitted in these venues, hospital orderlies, sports spectators, outdoor cafe aficionados, and beach goers might have to be restricted to the ranks of the non-asthmatic.

Have you ever had dinner in an outdoor café in Paris, Athens, Las Palmas, or Salt Lake City spoiled by smokers at adjacent tables? Have you ever had to move your blanket on a public beach because someone suddenly started smoking upwind, replacing clean salt air with irritating smoke? Smoking has no social value other than to create unnecessary work for physicians, and windfall profits for morticians. Even if outdoor environmental tobacco smoke were no more hazardous than dog excrement stuck to the bottom of a shoe, in many places laws require dog owners to avoid fouling public areas. Is this too much to ask of smokers?

RepaceAssociates, Inc, JAMES REPACE

101 Felicia Lane

Bowie, MD 20720, USA;

$<$ www.repace.com> 